\title{
Hydrothermal synthesis of monocopper sulfide for hydrogen peroxide-assisted photodegradation of paraquat
}

\author{
Rattabal Khunphonoi ${ }^{1,2,3}$, Kitirote Wantala ${ }^{1,3}$, Nurak Grisdanurak ${ }^{4^{\dagger}}$ \\ ${ }^{1}$ Research Center for Environmental and Hazardous Substance Management (EHSM), Faculty of Engineering, Khon Kaen University, Khon Kaen \\ 40002, Thailand \\ ${ }^{2}$ Department of Environmental Engineering, Faculty of Engineering, Khon Kaen University, Khon Kaen 40002, Thailand \\ ${ }^{3}$ Chemical Kinetics and Applied Catalysis Laboratory (CKCL), Faculty of Engineering, Khon Kaen University, Khon Kaen 40002, Thailand \\ ${ }^{4}$ Center of Excellence in Environmental Catalysis and Adsorption, Faculty of Engineering, Thammasat University, Pathumthani, 12120 Thailand
}

\begin{abstract}
Copper sulfide was prepared by a hydrothermal method at $130^{\circ} \mathrm{C}$. The copper to sulfur molar ratio (6-10) and ageing time (24-72 $\mathrm{h}$ ) were their synthesis parameters. The obtained materials were characterized by X-ray diffraction (XRD), Scanning electron microscopy (SEM), transmission electron microscope (TEM), UV-DR spectroscopy and X-ray photoelectron spectroscopy (XPS). In order to obtain monocopper sulfide, CuS, named as covellite, the molar recipe ratio of sulfur to copper should be less than 8 in any hydrothermal ageing time. The morphology showed spherical-like structure with energy band gap of 1.88-2.04 eV. CuS was tested for its photocatalytic degradation of paraquat under visible light irradiation. It exhibited excellent activities in the presence of $\mathrm{H}_{2} \mathrm{O}_{2}$. The kinetic of paraquat degradation was also investigated using Langmuir-Hinshelwood-Hougen-Watson (LHHW) model. The reaction rate constant was three times higher than $\mathrm{TiO}_{2}$ under the same studied conditions.
\end{abstract}

Keywords: CuS, Solvothermal method, Photocatalytic reaction, Paraquat, Visible light

\section{Introduction}

Copper sulfide has attracted interest due to the excellence in its optical, electronic, physical and chemical properties [1]. It can be applied in many applications such as $p$-type semiconductor in solar cell [2, 3], adsorbents and catalysts for sustainable environmental treatment issues. Copper sulfide could be existed in several forms such as covellite (CuS), chalcocite $\left(\mathrm{Cu}_{2} \mathrm{~S}\right)$ and villamaninite $\left(\mathrm{CuS}_{2}\right)$. Copper sulfide can be prepared by many techniques such as hydrothermal or solvothermal methods $[4,5]$, microwave irradiation [6, 7], sonication [8], sol-gel precipitation [9]. Among those methods, hydrothermal and solvothermal techniques are simple, low cost and friendly to environment.

According to a narrow bandgap ranging of copper sulfide, 1.27 - $1.75 \mathrm{eV}$ [10], copper sulfide could be utilized as a photocatalyst. The photocatalytic degradation by this material was reported over several dye solutions, such as methylene blue (MB), rhodamine B (RhB), malachite green (MG), methyl red (MR), methyl orange
(MO) and eosin (E) [11]. Since monocopper sulfide $(\mathrm{CuS})$ is a preference form among those three forms, the study of precursor ratios of $\mathrm{Cu}$ and $\mathrm{S}$ in the synthesis recipe, therefore, has been interested [12]. Auyoong et al. [13] also mentioned that mole ratio of $\mathrm{Cu}: \mathrm{S}$ provided an important role in controlling the form of copper sulfide. Adhikari et al. [14] examined the photoreactivity of $\mathrm{CuS}$ and $\mathrm{Cu}_{2} \mathrm{~S}$ phases over 4-Chlorophenol. According to the spectra obtained from photoluminescence spectroscopy, it was reported that $\mathrm{Cu}_{2} \mathrm{~S}$ showed less degradation activity than $\mathrm{CuS}$, and high recombination rate of photogenerated charges was concluded as one possible cause. Moreover, dicopper sulfide could be also contaminated in the final product during the synthesis of monocopper sulfide [15, 16]. The recipe range of copper to sulfur ratio in monocopper sulfide synthesis without forming of dicopper sulfide should be interestingly investigated.

Even though organic species in wastewater can be degraded effectively by photodegradation technique, some intermediates found in the effluent have been highly toxic or even higher toxic
This is an Open Access article distributed under the terms of the Creative Commons Attribution Non-Commercial License (http://creativecommons.org/licenses/by-nc/3.0/) which permits unrestricted non-commercial use, distribution, and reproduction in any medium, provided the original work is properly cited.

Copyright (C) 2021 Korean Society of Environmental Engineers
Received December 04, 2019 Accepted March 06, 2020

${ }^{\dagger}$ Corresponding author

Email: gnurak@engr.tu.ac.th

Tel: +66-89-4558560

ORCID: 0000-0002-9525-522X 
than the initial organic species [17]. To overcome these problems, another advanced oxidation, like ozonation, and $\mathrm{H}_{2} \mathrm{O}_{2}$ addition could be simultaneously collaborated with, which could assist the degradation of the target species completely [18-20].

Considering an agricultural country like Thailand, herbicide could be used as a probe chemical, which could provide direct information toward the upscale applications. In general, paraquat (1,1-dimethyl-4,4'-bipyridylium chloride) has been widely used to control weeds in any plantation area, and commonly contaminated to the wastewater effluent. Based on the excellent weed control properties, the consumption has become higher every year. Certainly, paraquat is highly toxic to human and environment via several exposure routes. Several organizations, therefore, have initiated highly strict regulations for the formulations, uses, and releases of paraquat [21].

In this research, synthesis factors, including ageing temperature, ageing time and $\mathrm{Cu}$ to $\mathrm{S}$ ratio, of copper sulfide nanoparticles by hydrothermal method were investigated. The characteristics of synthesized materials were observed through XRD, SEM, TEM, UV-DR and XPS. In addition, photodegradation of paraquat with and without $\mathrm{H}_{2} \mathrm{O}_{2}$ was carried out to examine the improvement of photocatalysis by $\mathrm{H}_{2} \mathrm{O}_{2}$ addition. Kinetics of decomposition were also investigated on paraquat degradation under visible irradiation.

\section{Material and Methods}

Copper (II) chloride dehydrate $\left(\mathrm{CuCl}_{2} \cdot 2 \mathrm{H}_{2} \mathrm{O}\right.$, Carlo Erba Reagents, $\geq 98 \%)$, Hexadecyl trimethyl ammonium bromide $\left(\mathrm{CH}_{3}\left(\mathrm{CH}_{2}\right)\right.$ $15 \mathrm{~N}(\mathrm{Br})\left(\mathrm{CH}_{3}\right)_{3}$, Acros Organics, $\geq 99 \%$ ) and sodium sulfide nonahydrate $\left(\mathrm{Na}_{2} \mathrm{~S} \cdot 9 \mathrm{H}_{2} \mathrm{O}\right.$, Carlo Erba Reagents, $\left.\geq 99.9 \%\right)$ were used as starting materials for copper sulfide preparation. Methyl viologen hydrate or paraquat $\left(\mathrm{C}_{12} \mathrm{H}_{14} \mathrm{Cl}_{2} \mathrm{~N}_{2} \cdot \mathrm{xH}_{2} \mathrm{O}\right.$, Sigma-Aldrich, $\left.\geq 98 \%\right)$ and hydrogen peroxide solution $\left(\mathrm{H}_{2} \mathrm{O}_{2}\right.$, Carlo Erba Reagents, 30 wt\% in water) were used as organic probe and electron accepter, respectively, for the photocatalytic activity of the CuS.

\subsection{Synthesis of CuS}

The preparation of CuS synthesis was adapted from Saranya and Nirmala Grace [22]. A mixture of copper chloride and hexadecyl trimethyl ammonium bromide solution was prepared. A solution of sodium sulfide nonahydrate was added into the prepared copper solution. The ratios of copper to sulfur in the final solution were varied on molar ratio basis of 1:6, 1:8 and 1:10. After the mixing, the solution was stirred for $30 \mathrm{~min}$ and transferred into a teflon-lined stainless steel autoclave for further hydrothermal ageing at $130^{\circ} \mathrm{C}$ in an oven. The autoclave was cured for 24,48 and $72 \mathrm{~h}$, afterwards, it was cooled down to room temperature before collecting the sample. The as-synthesized material was removed from the tefloncontainer to centrifugal tubes. The precipitate was isolated by using a centrifuge and washed with deionized water and ethanol for several times until the solution became transparent. Then, the precipitate was dried in a vacuum oven at $60^{\circ} \mathrm{C}$ for $12 \mathrm{~h}$. Finally, the samples in black powder form were obtained. The as-synthesized samples were assigned as $\mathrm{CuS}(\mathrm{x}-\mathrm{y})$; where $\mathrm{x}$ represents molar ratio of sulfur to copper and y represents ageing period in h. For example:
CuS(6-24) means CuS synthesized under copper to sulfur molar ratio basis of 1:6 and hydrothermally aged for $24 \mathrm{~h}$.

\subsection{Characterization}

The crystalline structure of the synthesized material was identified by an X-ray diffractometer (BrukerAXS Model D8 Discover, Germany) equipped with a $\mathrm{Cu} K_{\mathrm{a}}$ monochromatized radiation source in the range of $2 \theta$ from $20^{\circ}$ to $60^{\circ}$. Scanning electron microscope (SEM, JEOLJSM-6610LV, Japan) and transmission electron microscope (TEM, FEI Tecnai G2 20, Oregon, USA) were used to observe their morphologies of the synthesized materials. The optical property of CuS was studied by UV-diffuse reflectance absorption spectrometer (Hitachi model U-3501, Japan). Surface analysis by X-ray photoelectron spectroscopy (XPS, AXIS ULTRA ${ }^{\mathrm{DLD}}$, Kratos analytical, UK) was performed with X-ray hybrid mode $700 \times 300 \mu \mathrm{m}$ spot area and a monochromatic $\mathrm{Al} K \alpha_{1,2}$ radiation at $1.4 \mathrm{keV}$. The radiation source was operated at $15 \mathrm{kV}$ and $150 \mathrm{~W}$. A base pressure in the XPS chamber was set at $5 \times 10^{-9}$ torr.

\subsection{Photocatalytic Activity Tests}

The photocatalytic activity of CuS was evaluated over paraquat solution under visible light irradiation. The photocatalytic reaction was performed in a 1,000 $\mathrm{mL}$ double-jacket cylindrical vessel. The reactor was fixed $30 \mathrm{~cm}$ away from a $6 \mathrm{~W}$ light emitting diode lamp (6W-E27, Philips, Germany). The solution was maintained at $25^{\circ} \mathrm{C}$. The light intensity was monitored by a solarimeter (SL100, Kimo, France) and a UV meter (UV-meter 5.0, Solartech, USA). It was confirmed that only visible light intensity of $6 \mathrm{~W} / \mathrm{m}^{2}$ was observed. The initial concentration range of paraquat solution were of $0.16-0.38 \mathrm{mM}(40-100 \mathrm{mg} / \mathrm{L})$. After adding the studied catalyst into the solution, the mixed solution was magnetically stirred in the dark for $1 \mathrm{~h}$ prior to turning the light on. One $\mathrm{mL}$ of hydrogen peroxide (30 wt\%) was initially added into the solution [19, 23]. For a time interval of $20 \mathrm{~min}$, one $\mathrm{mL}$ of sample was drawn out by a syringe and filtered by a PTFE- Millipore disk $(0.45 \mu \mathrm{m})$ to remove any suspended catalyst particles before the analysis. The remaining paraquat concentration was analyzed by a UV-vis spectrophotometer (JASCO-V630, Japan) under the wavelength of 257 $\mathrm{nm}$. The concentration of paraquat also was double checked with a high performance liquid chromatography (HPLC, Agilent Technologies, USA) equipped with Hypersil C18 ODS (4.0 125 $\mathrm{mm}, 5 \mu \mathrm{m}$ ) column and diode-array detector (HPLC-DAD 1200 series, Agilent Technologies, USA) with a UV-detector set at $\lambda$ $=258 \mathrm{~nm}$. The column temperature and injection volume were set at $25^{\circ} \mathrm{C}$ and $80 \mu \mathrm{L}$, respectively.

\section{Results and Discussion}

\subsection{Characterization of CuS}

Nine samples of prepared catalysts $\mathrm{CuS}(\mathrm{x}-\mathrm{y})$ were characterized by XRD, firstly. The XRD patterns of those catalysts are presented in Fig. 1. It was found that all catalysts showed sharp crystalline peaks $(2 \theta)$ at $27.9^{\circ}, 32.4^{\circ}, 46.4^{\circ}$ and $55.1^{\circ}$. In regard to JCPDS card no.06-0464, they correspond with the planar of (101), (103), 


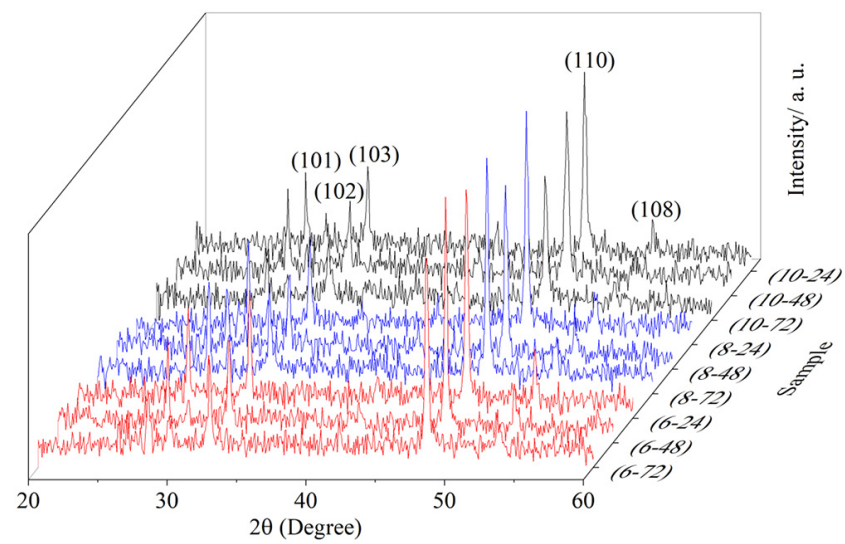

Fig. 1. XRD patterns of copper sulfide prepared in a variety of sulfite ratios and ageing times.

(110) and (108) of CuS or covellite phase [24, 25]. Any formation of $\mathrm{Cu}_{2} \mathrm{~S}$ and $\mathrm{CuS}_{2}$ in this range of synthesis conditions could not be observed. Considering in all samples, the materials synthesized under adding low amount of sulfite for any ageing time [CuS(6-y)] provided stronger sharp peaks, comparative to those under higher amount of sulfite adding for any ageing time [CuS(8-y) and [CuS(10-y)]. It was also indicated that ageing period of $24 \mathrm{~h}$ would be sufficient to stabilize copper sulfide in covellite phase. According to the XRD patterns, the average crystallite size of catalyst could be approximated by Scherrer's equation to be 32.52 $\pm 3.71 \mathrm{~nm}[26]$.

Morphologies of copper sulfide in different synthesis conditions were studied by SEM and TEM. The images are shown in Fig. 2. Three structural patterns, including spherical, plate-like and rod-like shape, could be observed. The particles shown in sample $\mathrm{CuS}(6-\mathrm{y})$ were formed mostly in spherical type. The distributions of rode-like and plate-like shape for CuS(6-y) were also found, but the distributions were found better when the synthesis were done with higher content of sulfur [CuS(8-y) and $\mathrm{CuS}(10-\mathrm{y})]$. In addition, obtained materials of $\mathrm{CuS}(6-48)$ and $\mathrm{CuS}(10-48)$ were selected and analyzed by TEM, as shown in Fig. 3. CuS(6-48) provided TEM image in plate-like structure with staggering to each other, while $\mathrm{CuS}(10-48)$ possessed more in rode-like structure. The observation of $\mathrm{CuO}$ layer was found in the sample with high sulfur ratio in recipe; $\mathrm{CuS}(10-48)$. On the other hand, $\mathrm{CuO}$ was not detected in $\mathrm{CuS}$ with low sulfur content, supported by the EDS results.
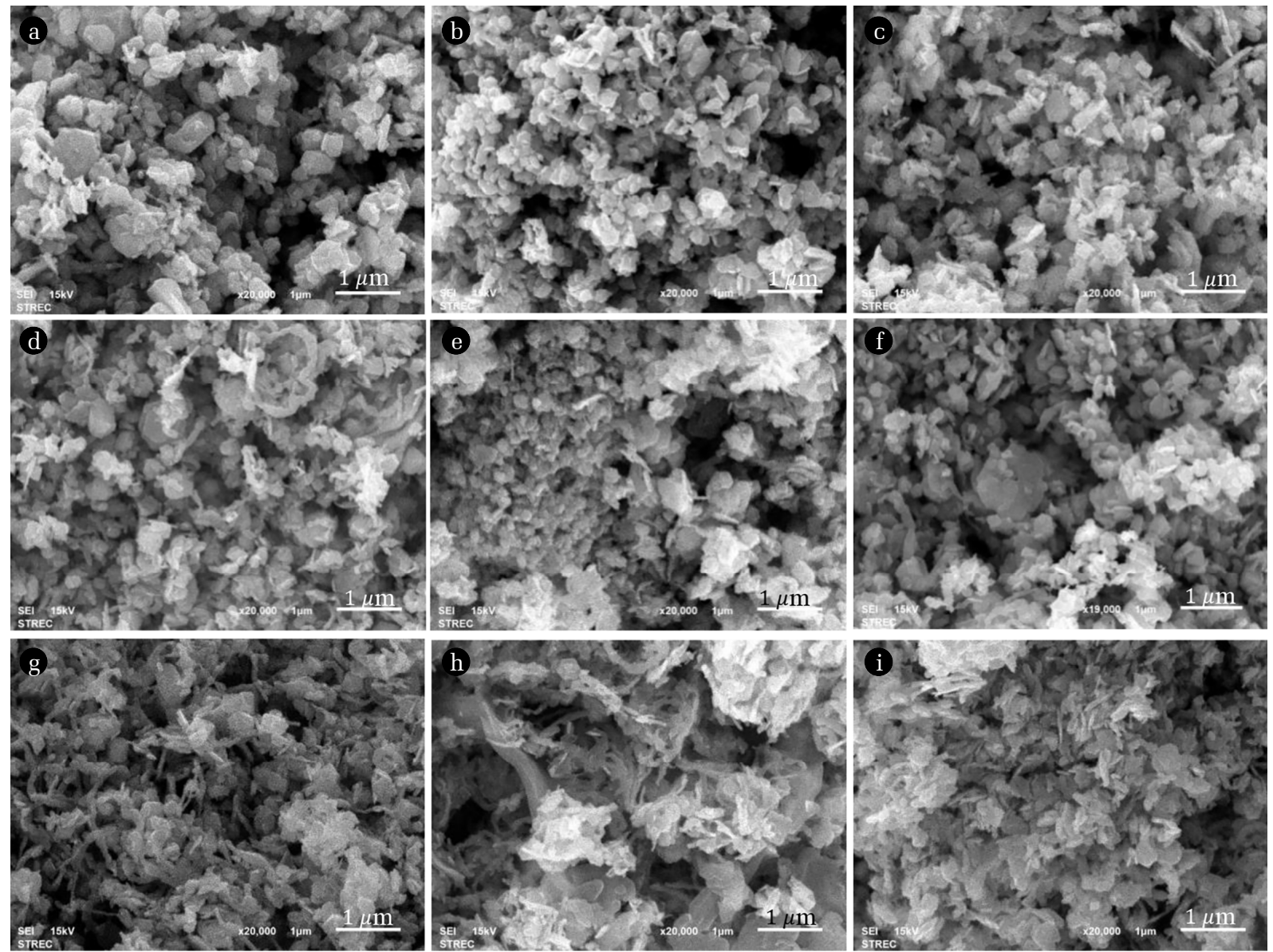

Fig. 2. SEM images of $\mathrm{CuS}(\mathrm{x}-\mathrm{y})$ prepared at $130^{\circ} \mathrm{C}$ under different sulfur contents and ageing temperatures. (a)-(c) CuS(6-24), (6-48), (6-72); (d)-(f) CuS(8-24), (8-48), (8-72); (g)-(i) CuS(10-24), (10-48), (10-72), respectively. 

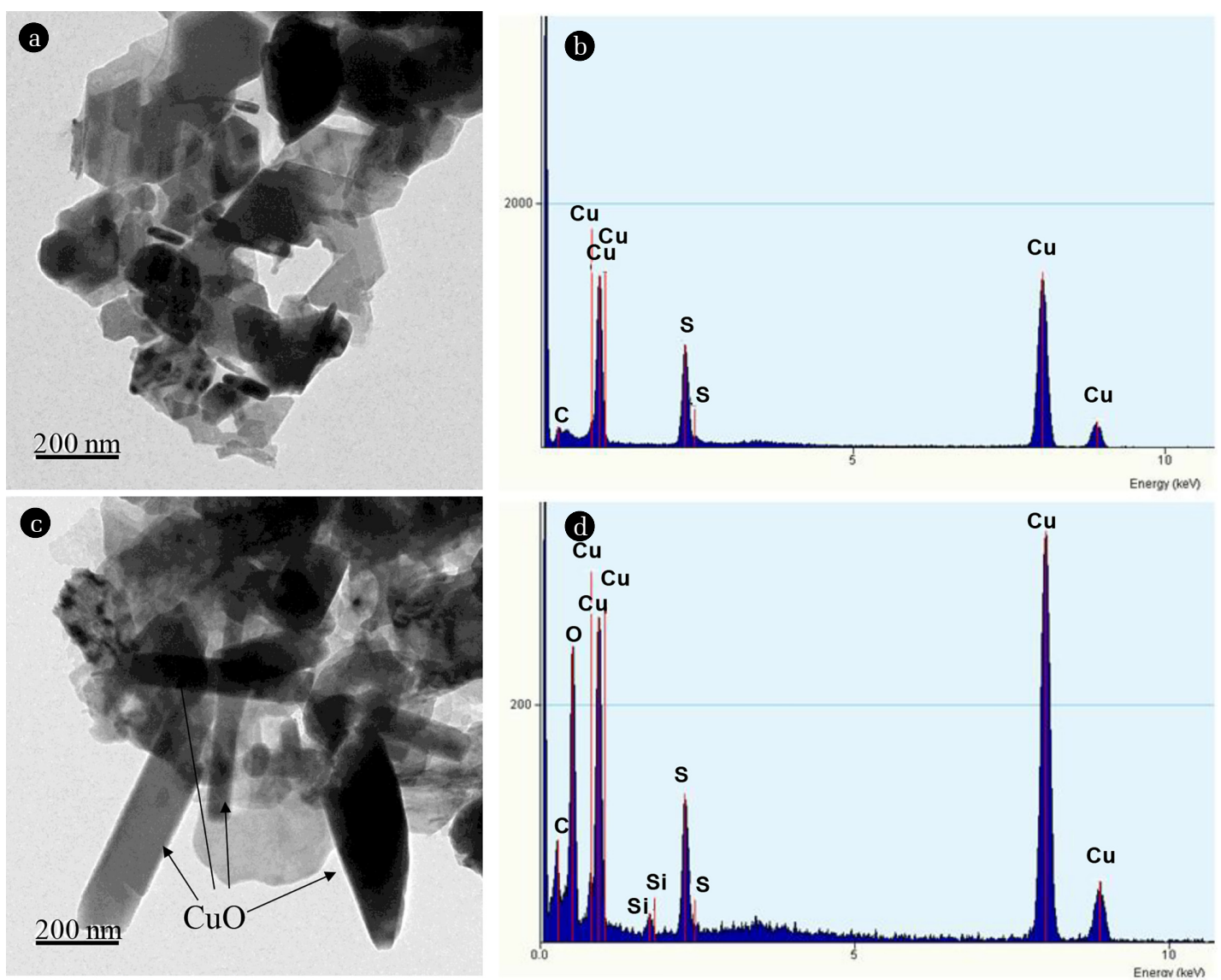

Fig. 3. TEM images of (a-b) CuS(6-48) and (c-d) CuS(10-48), attached with EDS results, respectively.

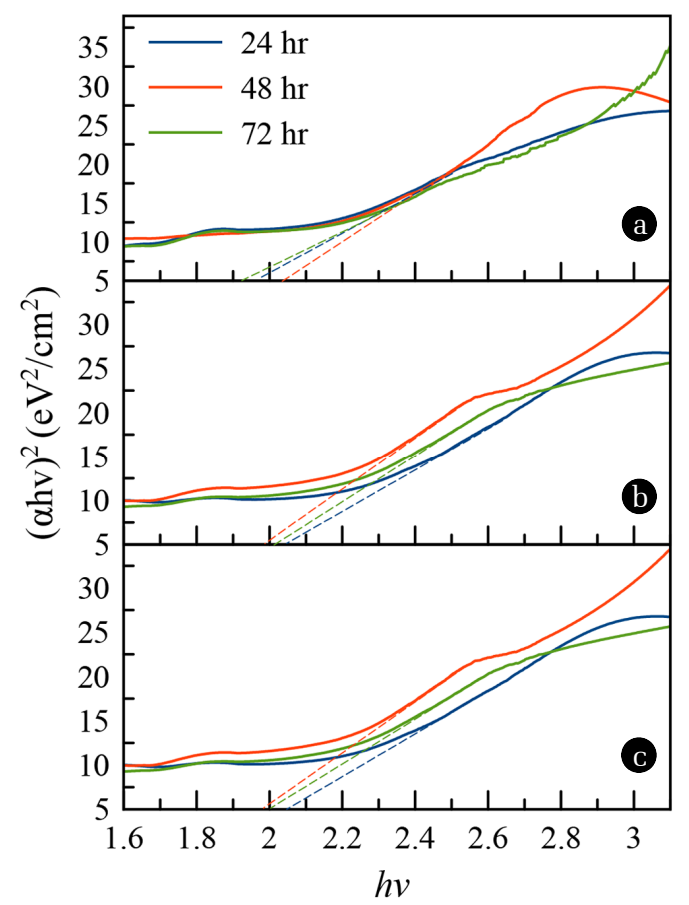

Fig. 4. UV-DR spectra and Tauc plots of CuS(6-y), CuS(8-y) and CuS(10-y).
To determine whether the material possesses good semiconducting property and be useful for the photocatalytic performance, the diffuse reflectance of UV should be measured. Fig. 4 shows UV-DRs spectra of all CuS samples. The Tauc plots were prepared to estimate the band gap energy of all samples. They were plots of $(\alpha h v)^{2}$, converted from spectra, versus their photon energy $(h v)$, where $\alpha$ is absorption coefficient, $h$ is Planck's constant, and $v$ represents light frequency. The tangent lines drawn through the maximum slopes were extrapolated, resulting in intersection values on the $\mathrm{X}$ axis [27]. It was found that the average band gap energy of synthesized catalysts was in the range of 1.88-2.04 eV.

As a result, different synthesis conditions on copper to sulfur ratio in the recipe were not significantly affect to the band gap energy. CuS was also analyzed for its chemical states by using X-ray photoelectron spectroscopy (XPS). Fig. 5(a) shows the XPS survey spectra of CuS(6-48) (Top view) and CuS(10-48) (Bottom . The peaks of $\mathrm{Cu} 2 \mathrm{p}_{3 / 2}$ and $\mathrm{Cu} 2 \mathrm{p}_{1 / 2}$ located at $932.9 \mathrm{eV}$ and 952.7 $\mathrm{eV}$ are corresponding to $\mathrm{Cu}_{2} \mathrm{~S}$. As the ratio of sulfur decreased, the $\mathrm{Cu} 2 \mathrm{p}$ peak shifted negatively to $932.5 \mathrm{eV}$. This phenomenon described the transformation from $\mathrm{Cu}_{2} \mathrm{~S}$ to $\mathrm{CuS}$ [23]. Besides, the peak of S-Cu bond was located at a binding energy $162.2 \mathrm{eV}$ [28] and the peak of S-S dimers was located at $163.6 \mathrm{eV}$ [29] (Fig. 5(b)). It was also found that the position of sulfide peak over CuS(6-y) was shifted negatively to approximately $161.8 \mathrm{eV}$, demonstrating 

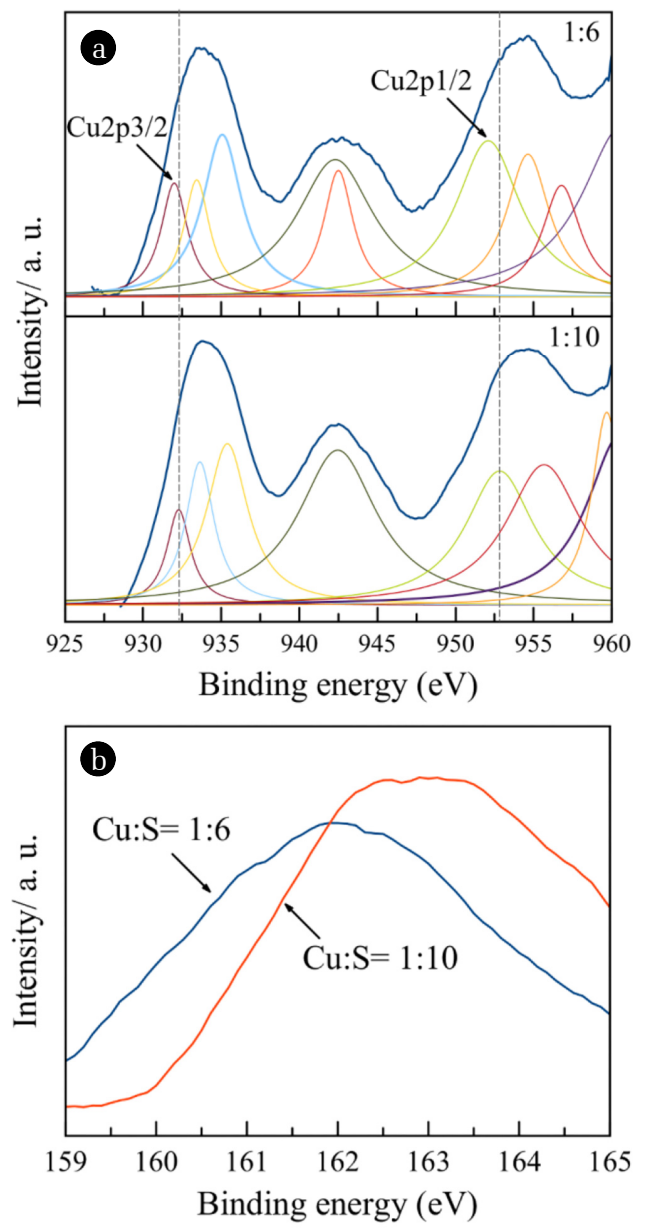

Fig. 5. XPS spectra of (a) $\mathrm{Cu} 2 \mathrm{p}$ and (b) $\mathrm{S} 2 \mathrm{p}$ from copper sulfide surface.

the decrease in average Cu-S bond length which is smaller in covellite than in chalcolite [30]. Therefore, it could be concluded that the ratio of copper to sulfur affecting on the formation of $\mathrm{CuS}$. $\mathrm{CuS}$ and $\mathrm{Cu}_{2} \mathrm{~S}$ were formed under the conditions of $\mathrm{CuS}(6-\mathrm{y})$ and $\mathrm{CuS}(10-\mathrm{y})$, respectively.

\subsection{Photocatalytic Activity of CuS}

The performance of copper sulfide on its photocatalytic activity was tested over paraquat, as a probe chemical. As explained by XPS, mixed recipe ratios of $\mathrm{Cu}$ and $\mathrm{S}$ could lead to different structures of $\mathrm{CuS}$ or $\mathrm{Cu}_{2} \mathrm{~S}$. All copper sulfide samples were tested for paraquat photodegradation under visible light irradiation. An initial concentration of paraquat was used at $0.16 \mathrm{mM}$ under $\mathrm{H}_{2} \mathrm{O}_{2}$ assistance. As shown in Fig. 6, paraquat was completely degraded within 180 min over CuS(6-y) and CuS(8-y). On the other hand, it was taken longer with $\mathrm{CuS}(10-\mathrm{y})$, approximately $240 \mathrm{~min}$ to complete the degradation. This would confirm that copper sulfide in covellite form (CuS) possessed higher photoactivity than chalcocite form $\left(\mathrm{Cu}_{2} \mathrm{~S}\right)$ [16]. This phenomenon is possible due to the effect of $\mathrm{Cu}_{2} \mathrm{~S}$ possesses high recombination rate of photogenerated charges, according to PL spectra explained by Adhikari et al. [14].

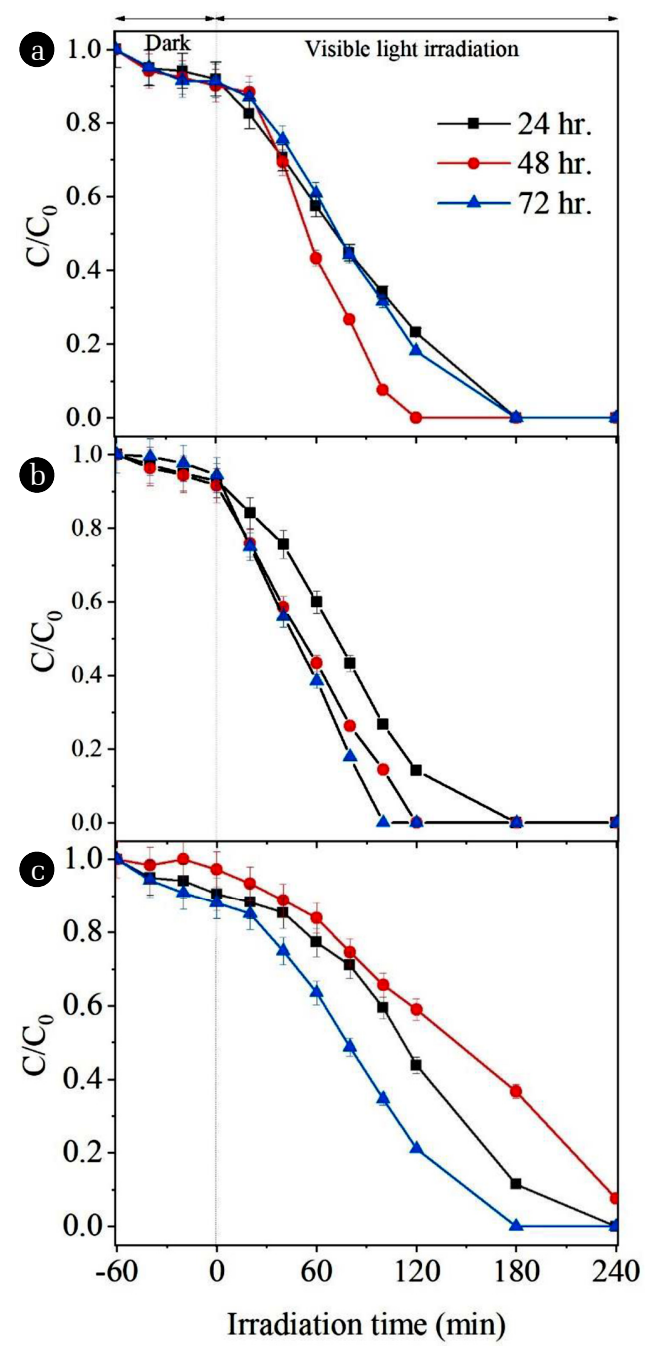

Fig. 6. Photocatalytic degradation profiles of $0.16 \mathrm{M}$ paraquat solution under visible light over CuS (a) (6-y) (b) (8-y) (c) (10-y) with catalyst dosage $1.0 \mathrm{~g} / \mathrm{L}$ and $\mathrm{H}_{2} \mathrm{O}_{2} 1 \mathrm{~mL}$ (30 wt\%).

It has been proved previously that covellite form $(\mathrm{CuS})$ was preferential to the photocatalytic reaction, therefore, $\mathrm{CuS}(6-48)$ was selected as a representative. The comparison of its performance was done against $\mathrm{TiO}_{2}$ powder. Fig. 7 shows the concentration profiles of the studied materials including the blank test. Prior to the photocatalytic test, the solution was kept in the dark environment for $1 \mathrm{~h}$, providing sufficient adsorption on the surface of materials. As observed, paraquat was disappeared onto the surface of $\mathrm{TiO}_{2}$ higher than $\mathrm{CuS}$. It was corresponding to the much higher surface area of $\mathrm{TiO}_{2}\left(50 \mathrm{~m}^{2} / \mathrm{g}\right)$ comparing to that of $\mathrm{CuS}$ (ca. 4.5 $\mathrm{m}^{2} / \mathrm{g}$ ).

Under visible irradiation, paraquat was barely degraded without photocatalyst, reflecting that paraquat was quite stable. It could be seen that the concentration of paraquat decreased little bit (ca. 2-3 \%) in the environment of either $\mathrm{CuS}$ or $\mathrm{H}_{2} \mathrm{O}_{2}$. The unsatisfactory performance of $\mathrm{CuS}$ was probably caused by a rapid recombination of photogenerated charges of $\mathrm{CuS}$ [24]. 


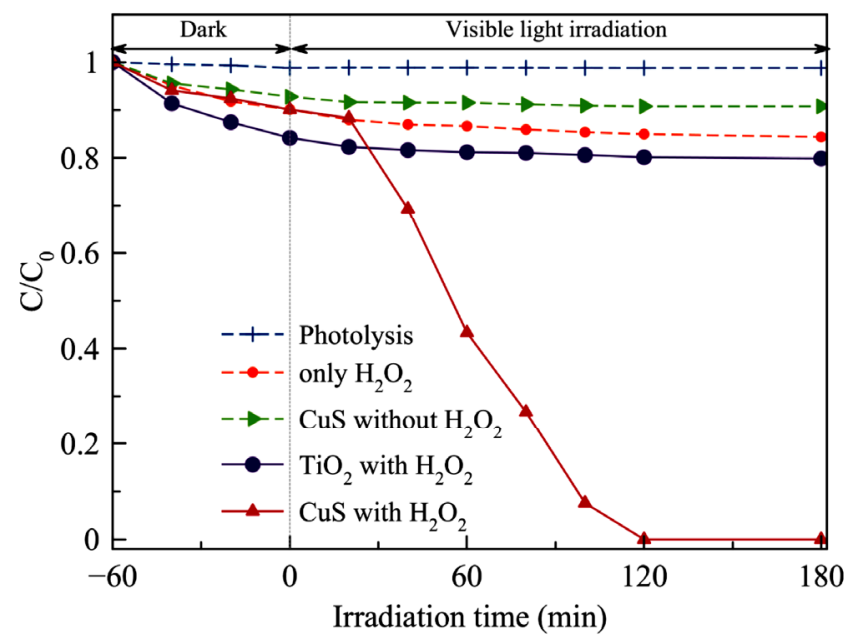

Fig. 7. Photocatalytic degradation profiles of $0.16 \mathrm{mM}$ paraquat solution

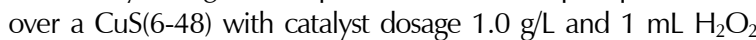
(30 wt\%) under visible light.

Applying a little amount of $\mathrm{H}_{2} \mathrm{O}_{2}$ into both cases $\left(\mathrm{TiO}_{2}\right.$ and $\mathrm{CuS}$ ), the difference of paraquat degradations could be noticed. Paraquat was degraded significantly higher over $\mathrm{CuS}$ assisted with $\mathrm{H}_{2} \mathrm{O}_{2}$ than over $\mathrm{TiO}_{2}$ assisted with $\mathrm{H}_{2} \mathrm{O}_{2}$. A complete degradation of paraquat was found over $\mathrm{CuS}$ with $\mathrm{H}_{2} \mathrm{O}_{2}$ within $2 \mathrm{~h}$ irradiation, while only $5 \%$ taken place over $\mathrm{TiO}_{2}$ with $\mathrm{H}_{2} \mathrm{O}_{2}$. The poor performance of $\mathrm{TiO}_{2}$ was probably due to low photon energy (hv) applied from visible light irradiation. The photo energy was not adequate to strike electrons from the valence band to generate any active species [1]. Thus, the declination of paraquat concentration should be based on the adsorption on the surface. Considering $\mathrm{CuS}$ assisted with $\mathrm{H}_{2} \mathrm{O}_{2}$, it seemed that the presence of $\mathrm{H}_{2} \mathrm{O}_{2}$ played an important role to energize the catalytic degradation activity of $\mathrm{CuS}$. It was expected that two mechanisms would be taken place. One was that $\mathrm{H}_{2} \mathrm{O}_{2}$ enhanced the reaction through Fenton-like and photo-fenton reactions. Regarding the former reaction, the $\mathrm{Cu}^{+}$in the $\mathrm{CuS}$ could react with $\mathrm{H}_{2} \mathrm{O}_{2}$ to generate hydroxyl radicals, and further improve the photocatalytic property to a Fenton-like reaction [31]. The photo-fenton reaction as the following mechanism, $\mathrm{H}_{2} \mathrm{O}_{2}$ acted as an efficient electron acceptor reacting with photogenerated electrons to promote the separation of the photogenerated electron and hole and additionally produce hydroxyl radicals [23, 32]. Consequently, paraquat would react with hydroxyl radicals both generated from Fenton-like reactions and photocatalysis. The concentration of remaining paraquat was reconfirmed by HPLC, as shown in Fig. 8. It illustrates paraquat HPLC peaks during photodegradation time; 0-40-80-120 min. The results were corresponded with those shown in Fig. 7. Moreover, the intermediate peak was not observed.

\subsection{Kinetic Study}

The kinetic study of photocatalytic reaction of CuS was evaluated over $\mathrm{CuS}(6-48)$ using an initial rate technique. Various initial concentrations of paraquat solutions of $0.08,0.16,0.24,0.32$ and 0.40 $\mathrm{mM}$ were performed for the kinetics investigation.

The Langmuir-Hinshelwood-Hougen-Watson (LHHW) kinetic model was applied to the photodegradation as shown in Eq (1).
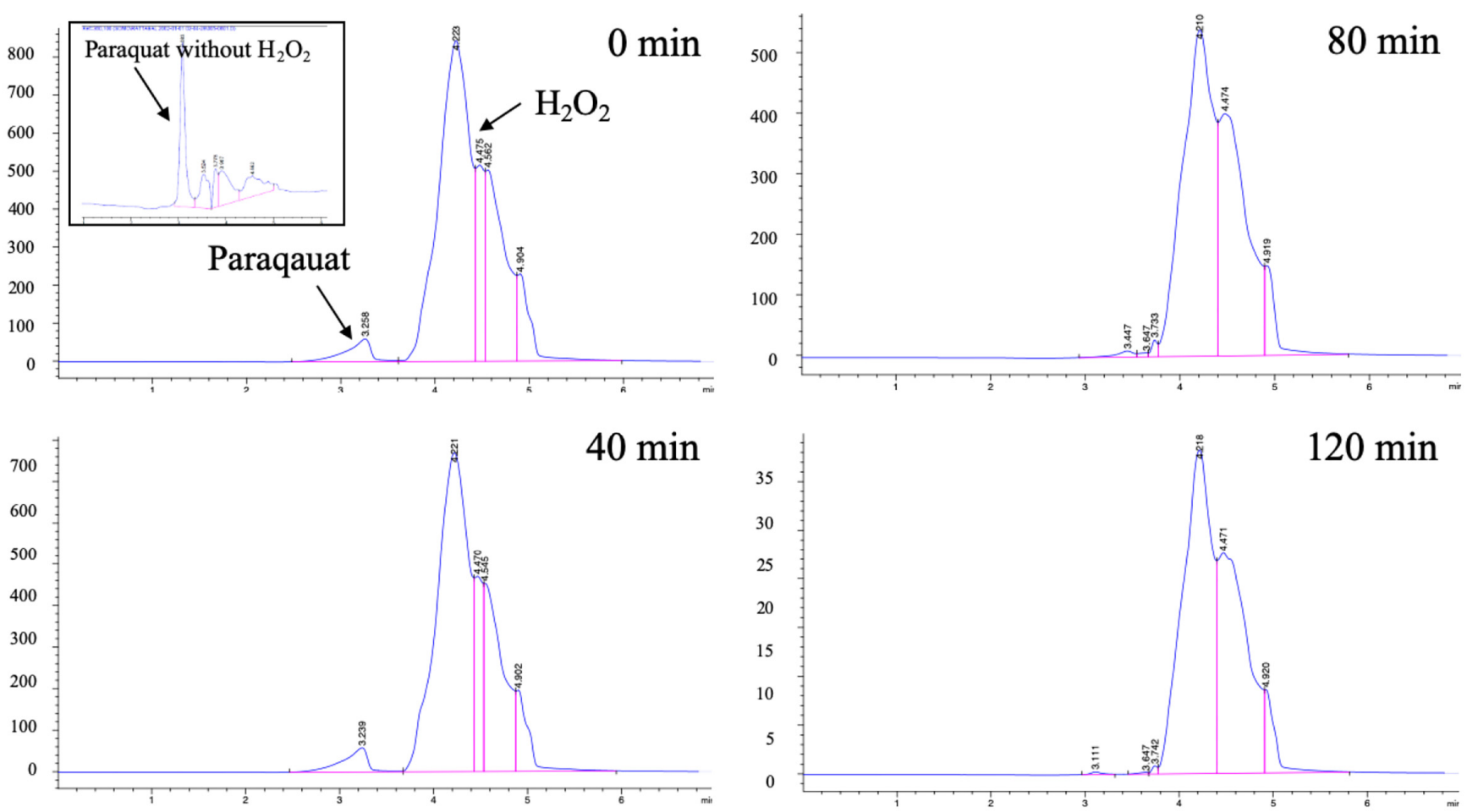

Fig. 8. HPLC chromatograms of paraquat $\left(0.16 \mathrm{mM}\right.$ paraquat solution; CuS(6-48) with catalyst dosage $1.0 \mathrm{~g} / \mathrm{L}$ and $\left.1 \mathrm{~mL} \mathrm{H}_{2} \mathrm{O}_{2}(30 \mathrm{wt} \%)\right)$ along time on stream. 
By applying an initial rate technique, all products would be neglected and the rate expression could be written as Eq. (2). To evaluate adsorption equilibrium constant and the surface reaction rate constant, Eq. (2) was rearranged into a linear form, as shown in Eq. (3).

$$
\begin{gathered}
-r_{\text {paraq }}=\frac{k C_{\text {paraq }}-k^{\prime} C_{\text {prod } i}}{1+K_{A} C_{\text {paraq }}+K_{\text {prod } i} C_{\text {prod } i}} \\
-r_{\text {paraq }}^{o}=\frac{k C_{\text {paraq }}^{o}}{1+K_{A} C_{\text {paraq }}^{o}} \\
\frac{1}{-r_{\text {paraq }}^{o}}=\frac{1}{k C_{\text {paraq }}^{o}}+\frac{K_{A}}{k}
\end{gathered}
$$

Where a subscription "o" represents an initial state.

Fig. S1 shows the plot of $\frac{1}{-r_{\text {paraq }}^{o}}$ versus $\frac{1}{C_{\text {paraq }}^{o}}$. Eventually, adsorption equilibrium constant $\left(K_{a}\right)$ and the surface reaction rate constant $\left(k_{r}\right)$ of paraquat degradation were obtained as $10.34 \mathrm{mM}^{-1}$ and $2.5 \times 10^{-3} \mathrm{~min}^{-1}$, respectively.

\section{Conclusions}

In the synthesis of copper sulfide by hydrothermal method, the recipe ratio of copper to sulfide was important. It was found that higher portion of sulfide to copper than 8 would generate both forms of $\mathrm{CuS}$ and $\mathrm{Cu}_{2} \mathrm{~S}$. The photocatalytic performance of $\mathrm{CuS}$ [from sample $\mathrm{CuS}(6)$ and $\mathrm{CuS}(8)$ ] over paraquat was much better than a combination species of $\mathrm{Cu}_{2} \mathrm{~S}$ and $\mathrm{CuS}$ [from $\left.\mathrm{CuS}(10)\right]$. Ageing time was not as a significant factor in the synthesis. The obtained $\mathrm{CuS}$ was in nanoparticles and spherical-like structure, provided band gap energy of 1.88-2.04 eV. The photodegradation performance of $\mathrm{CuS}$ was tested over paraquat solution under the $\mathrm{H}_{2} \mathrm{O}_{2}$ assistance. The kinetic of paraquat photocatalytic degradation was revealed by the Langmuir-Hinshelwood-Hougen-Watson kinetic model. The surface reaction rate constant $(\mathrm{k})$ was found to be $2.5 \times 10^{-3} \mathrm{~min}^{-1}$, which is higher than that of $\mathrm{TiO}_{2}$.

\section{Acknowledgment}

This study was financially supported by Research and Technology Transfer Affairs of Khon Kaen University (KKU-Syn2561-005) and the young researcher development project of Khon Kaen University. The authors would like to extend our gratitude to Synchrotron Light Research Institute Public Organization, Thailand for XPS measurement (SUT-NANOTEC-SLRI: BL. 5.3).

\section{Author Contributions}

R. K. (Ph.D.) designed and carried out the experiments, contributed to the interpretation of the results, and co-prepared the manuscript.
K.W. (Assoc. Prof.) characterized the materials and analyzed the data. N.G. (Assoc. Prof.) supervised the project and co-wrote the manuscript.

\section{References}

1. Wang Y, Zhang L, Jiu H, Li N, Sun Y. Depositing of CuS nanocrystals upon the graphene scaffold and their photocatalytic activities. Appl. Surf. Sci. 2014;303:54-60.

2. Zhang W, Chen Z, Yang Z. An inward replacement/etching route to synthesize double-walled $\mathrm{Cu}_{7} \mathrm{~S}_{4}$ nanoboxes and their enhanced performances in ammonia gas sensing. Phys. Chem. Chem. Phys. 2009;11:6263-6268.

3. Cao H, Qian X, Wang C, Ma X, Yin J, Zhu Z. High symmetric 18-facet polyhedron nanocrystals of $\mathrm{Cu}_{7} \mathrm{~S}_{4}$ with a hollow nanocage. J. Am. Chem. Soc. 2005;127:16024-16025.

4. Zou J, Zhang J, Zhang B, Zhao P, Huang K. Low-temperature synthesis of copper sulfide nano-crystals of novel morphologies by hydrothermal process. Mater. Lett. 2007;61:5029-5032.

5. Gorai S, Ganguli D, Chaudhuri S. Morphological control in solvothermal synthesis of copper sulphides on copper foil. Mater. Res. Bull. 2007;42:345-353.

6. Liao XH, Chen NY, Xu S, Yang SB, Zhu JJ. A microwave assisted heating method for the preparation of copper sulfide nanorods. J. Cryst. Growth. 2003;252:593-598.

7. Yan X, Michael E, Komarneni S, Brownson JR, Yan ZF. Microwave-and conventional-hydrothermal synthesis of $\mathrm{CuS}$, SnS and ZnS: Optical properties. Ceram. Int. 2013;39:4757-4763.

8. Mousavi-Kamazani M, Salavati-Niasari M, Ramezani M. Preparation and characterization of $\mathrm{Cu}_{2} \mathrm{~S}$ nanoparticles via ultrasonic method. J. Clust. Sci. 2013;24:927-934.

9. Gurin VS, Prakapenka VB, Kovalenko DL, Alexeenko AA. Sol-gel derived silica films with ultrafine copper, copper sulfide and copper selenide particles. J. Sol-Gel Sci. Technol. 2003;26: 961-966.

10. Tanveer M, Cao C, Aslam I, et al. Effect of the morphology of $\mathrm{CuS}$ upon the photocatalytic degradation of organic dyes. RSC Adv. 2014;4:63447-63456.

11. Shamraiz U, Hussain RA, Badshah A. Fabrication and applications of copper sulfide (CuS) nanostructures. J. Solid State Chem. 2016;238:25-40.

12. Mathew SK, Rajesh NP, Ichimura M, Udayalakshmi. Preparation and characterization of copper sulfide particles by photochemical method. Mater. Lett. 2008;62:591-593.

13. Auyoong YL, Yap PL, Huang X, Abd Hamid SB. Optimization of reaction parameters in hydrothermal synthesis: a strategy towards the formation of CuS hexagonal plates. Chem. Cent. J. 2013;7:67.

14. Adhikari S, Sarkar D, Madras G. Hierarchical design of CuS architectures for visible light photocatalysis of 4-chlorophenol. ACS Omega. 2017;2:4009-4021.

15. He YB, Polity A, Österreicher I, et al. Hall effect and surface characterization of $\mathrm{Cu}_{2} \mathrm{~S}$ and $\mathrm{CuS}$ films deposited by $\mathrm{RF}$ reactive sputtering. Phys. B Condens. Matter. 2001;308-310:1069-1073.

16. Mousavi-Kamazani M, Zarghami Z, Salavati-Niasari M. Facile and novel chemical synthesis, characterization, and formation 
mechanism of copper sulfide $\left(\mathrm{Cu}_{2} \mathrm{~S}, \mathrm{Cu}_{2} \mathrm{~S} / \mathrm{CuS}, \mathrm{CuS}\right)$ nanostructures for increasing the efficiency of solar cells. J. Phys. Chem. C. 2016;120:2096-2108.

17. Hama Aziz KH, Mahyar A, Miessner H, et al. Application of a planar falling film reactor for decomposition and mineralization of methylene blue in the aqueous media via ozonation, Fenton, photocatalysis and non-thermal plasma: A comparative study. Process Saf. Environ. Prot. 2018;113:319-329.

18. Hama Aziz KH, Miessner H, Mueller S, et al. Comparative study on 2,4-dichlorophenoxyacetic acid and 2,4-dichlorophenol removal from aqueous solutions via ozonation, photocatalysis and non-thermal plasma using a planar falling film reactor. J. Hazard. Mater. 2018;343:107-115.

19. Andriantsiferana C, Mohamed EF, Delmas H. Sequential adsorption - photocatalytic oxidation process for wastewater treatment using a composite material $\mathrm{TiO}_{2} /$ activated carbon. Environ. Eng. Res. 2015;20:181-199.

20. Hama Aziz KH. Application of different advanced oxidation processes for the removal of chloroacetic acids using a planar falling film reactor. Chemosphere 2019;228:377-383.

21. Food and agriculture organization of the united nations. FAO specifications and evaluations for agricultural pesticides [internet]. Rome: Food and agriculture organization of the united nations; c2015 [cited 20 November 2019]. Available from: http://www.fao.org/agriculture/crops/core-themes/theme/pests/ jmps/en/

22. Saranya M, Nirmala Grace A. Hydrothermal Synthesis of CuS nanostructures with different morphology. JNanoR. 2012;18-19: 43-51.

23. Xu W, Zhu S, Liang Y, et al. Nanoporous CuS with excellent photocatalytic property. Sci Rep. 2015;5:18125.
24. Basu M, Nazir R, Fageria P, Pande S. Construction of CuS/Au heterostructure through a simple photoreduction route for enhanced electrochemical hydrogen evolution and photocatalysis. Sci. Rep. 2016;6:34738.

25. Li F, Wu J, Qin Q, Li Z, Huang X. Controllable synthesis, optical and photocatalytic properties of CuS nanomaterials with hierarchical structures. Powder Technol. 2010;198:267-274.

26. Khunphonoi R, Grisdanurak N. Mechanism pathway and kinetics of $p$-cresol photocatalytic degradation over titania nanorods under UV-visible irradiation. Chem. Eng. J. 2016;296: 420-427.

27. Kanchanatip E, Grisdanurak N, Thongruang R, Neramittagapong A. Degradation of paraquat under visible light over fullerene modified V-TiO 2 . React. Kinet. Mech. Catal. 2011;103:227-237.

28. Li J, Jiu T, Tao GH, et al. Manipulating surface ligands of Copper Sulfide nanocrystals: Synthesis, characterization, and application to organic solar cells. J. Colloid Interface Sci. 2014;419: 142-147.

29. Kurmaev EZ, Ek J-van, Ederer DL, et al. Experimental and theoretical investigation of the electronic structure of transition metal sulphides: CuS. J. Phys. Condens. Matter. 1988;10:1687.

30. Xie Y, Riedinger A, Prato M, et al. Copper sulfide nanocrystals with tunable composition by reduction of covellite nanocrystals with $\mathrm{Cu}^{+}$ions. J. Am. Chem. Soc. 2013;135:17630-17637.

31. Mi L, Wei W, Zheng Z, et al. Tunable properties induced by ion exchange in multilayer intertwined $\mathrm{CuS}$ microflowers with hierarchal structures. Nanoscale 2013;5:6589-6598.

32. Kitsiou V, Filippidis N, Mantzavinos D, Poulios I. Heterogeneous and homogeneous photocatalytic degradation of the insecticide imidacloprid in aqueous solutions. Appl. Catal. B Environ. 2009;86:27-35. 